\title{
A novel oocyte maturation trigger using 1500 IU of human chorionic gonadotropin plus 450 IU of follicle-stimulating hormone may decrease ovarian hyperstimulation syndrome across all in vitro fertilization stimulation protocols
}

\author{
Yanett Anaya $^{1}$ (D) Douglas A. Mata ${ }^{2} \cdot$ Joseph Letourneau $^{1} \cdot$ Hakan Cakmak $^{1}$ • \\ Marcelle I. Cedars ${ }^{1} \cdot$ Mitchell P. Rosen ${ }^{1}$
}

Received: 9 July 2017 / Accepted: 17 October 2017 / Published online: 30 October 2017

(C) Springer Science+Business Media, LLC 2017, Corrected publication November/2017

\begin{abstract}
Purpose Modification of the trigger used to induce final oocyte maturation in in vitro fertilization (IVF) is a major strategy used to reduce the risk of ovarian hyperstimulation syndrome (OHSS). A novel trigger composed of $1500 \mathrm{IU}$ of human chorionic gonadotropin (hCG) plus $450 \mathrm{IU}$ of folliclestimulating hormone (FSH) has been developed to reduce OHSS risk. This study compares outcomes of the novel trigger to conventional triggers used in high-risk OHSS patients undergoing IVF.

Methods In this retrospective cohort study, IVF cycles at high risk for OHSS based on a serum estradiol $>5000 \mathrm{pg} / \mathrm{ml}$ on trigger day conducted between January 2008 and February 2016 were evaluated. Oocyte maturation was induced with the novel trigger (1500 IU hCG plus 450 IU FSH) or a conventional trigger [3300 IU hCG, gonadotropin-releasing hormone agonist (GnRHa) alone, or GnRHa plus $1500 \mathrm{IU}$ hCG]. IVF cycle outcomes were compared. Trigger strategies were examined for associations with OHSS development using logistic regression.

Results Among 298 eligible IVF cycles identified, there were no differences in oocyte maturation, fertilization, embryo quality, or pregnancy outcomes among all triggers. After adjusting for serum estradiol level and number of follicles,
\end{abstract}

Yanett Anaya

yanett2121@gmail.com

1 Center for Reproductive Health and Division of Reproductive Endocrinology and Infertility, University of California, San Francisco, 499 Illinois Street, San Francisco, CA 94143, USA

2 Department of Pathology, Brigham and Women's Hospital, Harvard Medical School, 75 Francis Street, Boston, MA 02115, USA the novel trigger was associated with lower odds of OHSS symptom development compared to the $3300 \mathrm{IU}$ hCG and GnRHa plus hCG 1500 IU triggers $(p=0.007$ and 0.04 , respectively).

Conclusions This study suggests that 1500 IU hCG plus 450 IU FSH may be associated with decreased OHSS symptoms compared to conventional triggers, while producing similar IVF and pregnancy outcomes. More important, this novel trigger may provide a superior alternative in down-regulated cycles and in patients with hypothalamic dysfunction where GnRHa triggers cannot be utilized.

Keywords FSH co-trigger $\cdot \mathrm{hCG}$ trigger $\cdot$ In vitro fertilization (IVF) · Ovarian hyperstimulation syndrome (OHSS)

\section{Introduction}

Ovarian hyperstimulation syndrome (OHSS) is a significant and potentially serious complication of ovarian stimulation in in vitro fertilization (IVF). Risk factors for OHSS include young age, low body mass index (BMI), high antral follicle count (AFC), and polycystic ovarian syndrome [1-3]. OHSS is characterized by a broad spectrum of clinical signs and symptoms, including rapid weight gain, abdominal distention, persistent nausea, and shortness of breath $[4,5]$. Rare but life-threatening symptoms can include arterial and venous thromboembolism, renal failure, and acute respiratory distress syndrome [6-8]. It is difficult to assess the exact incidence of OHSS in IVF, but mild cases may occur in $20-33 \%$ of stimulated cycles, while moderate symptoms are experienced in $3-6 \%$ and severe forms in about $0.1-2 \%$ of stimulated cycles $[9,10]$. 
The pathogenesis of OHSS is thought to be related to excess production of vasoactive mediators from the ovaries, principally vascular endothelial growth factor (VEGF), which leads to increased vascular permeability $[11,12]$. As a result, there is extravasation of fluid from the intravascular compartment which leads to third spacing and hemo-concentration that can precipitate hypercoagulability and reduced end-organ perfusion $[13,14]$. Human chorionic gonadotropin (hCG), used to trigger final oocyte maturation in IVF, plays a key role in the development of OHSS. This causal relationship is based on findings that the syndrome does not develop when hCG is withheld and that increased dose exposure is associated with a higher OHSS risk [15]. The pathophysiology is likely due to the longer half-life of $h C G$ compared to endogenous luteinizing hormone (LH) (approximately $24 \mathrm{~h}$ vs. $60 \mathrm{~min}$, respectively) coupled with its higher affinity for $\mathrm{LH}$ receptors and increased intracellular effect permitting prolonged LH activity [16-20]. This results in increased vasoactive substances that mediate many of the pathological changes that occur in OHSS [21, 22].

Many different strategies have been described to circumvent the risk of OHSS, including cycle cancellation [23], coasting [24], instituting a "freeze-all" policy [25], posttrigger administration of dopamine agonists [26], intravenous albumin administration [27], and very commonly, modifying the ovulation trigger [28-30]. Given the higher potency of $\mathrm{hCG}$, one common approach is lowering the standard trigger dose of 10,000 international units (IU) of urinary hCG [31, 32]. However, the lowest effective hCG dose is unknown. Older studies have postulated that doses of $2000 \mathrm{IU}$ or lower could compromise IVF outcomes [31]. Another trigger alternative is to completely eliminate the use of exogenous hCG and administer gonadotropin-releasing hormone agonist (GnRHa) to induce an endogenous gonadotropin surge $[28,33]$. Although its use has demonstrated a significant decrease in OHSS compared to hCG [34], GnRHa cannot be used in downregulated stimulation cycles or in patients with hypothalamic dysfunction. Furthermore, there is a small but clinically important risk of GnRHa trigger failure in normo-ovulatory patients [35-38], which has hindered the universal adoption of the GnRHa trigger to prevent OHSS.

We hypothesized that mimicking the naturally occurring FSH surge during the LH surge with a 450 IU FSH cotrigger may potentiate hCG activity [39-46], allowing a lower hCG trigger dose of 1500 IU to be effectively utilized to reduce OHSS risk while not compromising IVF outcomes compared to alternative risk-reducing triggers. In the present study, we assessed OHSS risk, IVF outcomes, and pregnancy outcomes in patients at high risk for OHSS, defined by a serum estradiol $\left(\mathrm{E}_{2}\right)$ level $>5000 \mathrm{pg} / \mathrm{ml}$ on the day of trigger, who received either one of three conventional alternative triggers (3300 IU of hCG, GnRHa alone, or GnRHa plus 1500 IU of hCG) or a novel trigger composed of $1500 \mathrm{IU}$ of urinary hCG plus $450 \mathrm{IU}$ of FSH.

\section{Materials and methods}

This retrospective cohort study evaluated women undergoing IVF treatment at the Center for Reproductive Health at the University of California, San Francisco (UCSF), between January 2008 and February 2016. We reviewed autologous and donor IVF cycles plus elective oocyte cryopreservation cycles that were determined to be at high risk of developing severe OHSS based on a serum $E_{2}$ level $>5000 \mathrm{pg} / \mathrm{ml}$ on the day of trigger. Subjects received one of three conventional alternative trigger strategies or the novel trigger, as outlined above, to reduce the OHSS risk. The inclusion criteria were adapted from a prediction model using a threshold $\mathrm{E}_{2}$ $>5000 \mathrm{pg} / \mathrm{ml}$ and $>18$ follicles counted on trigger day to predict patients with an $83 \%$ sensitivity and $84 \%$ specificity for developing severe OHSS in GnRH antagonist cycles triggered with a standard dose of hCG [47]. Although the number of follicles counted on trigger day was not part of our inclusion criteria, the average number was 33.5 among all groups. Both down-regulated and GnRH antagonist stimulation protocols were included. Patients who underwent "coasting" to decrease OHSS risk were excluded from the study. This study was reviewed and approved by the UCSF Internal Review Board.

Patients underwent controlled ovarian stimulation with exogenous gonadotropins. The initial starting gonadotropin dose was based on the patient's age, BMI, and baseline AFC. Final oocyte maturation was triggered when adequate follicular development was achieved per standard of care. In general, all patients were triggered when two lead follicles measured $18 \mathrm{~mm}$ or greater and the general cohort of follicles measured greater than $13 \mathrm{~mm}$, with consideration of the cycle day and the serum $E_{2}$ level. The triggers administered were (a) $1500 \mathrm{IU}$ of urinary hCG plus $450 \mathrm{IU}$ of purified or recombinant FSH (novel trigger), (b) $3300 \mathrm{IU}$ of urinary hCG, (c) GnRHa only (4 mg of leuprolide acetate), or (d) GnRHa plus $1500 \mathrm{IU}$ of urinary hCG. Patients using a GnRHa trigger with suspicion for potential hypothalamic dysfunction received a supplemental low-dose hCG co-trigger to overcome potential GnRHa trigger failure. Patients on down-regulated protocols were only candidates for $3300 \mathrm{IU}$ of hCG or the novel trigger. Triggers were selected at the discretion of the clinician, largely based on the risk for OHSS.

Oocyte retrieval was performed under ultrasound guidance $36 \mathrm{~h}$ after trigger administration. Oocytes were either fertilized by conventional insemination or, if indicated, by intracytoplasmic sperm injection (ICSI). Oocyte maturity was assessed after cumulus cell stripping in patients undergoing ICSI or elective oocyte cryopreservation. Fertilization was assessed $18 \mathrm{~h}$ after insemination or sperm injection. Embryos were cultured in sequential media to cleavage or blastocyst stage based on institutional laboratory criteria. Embryo morphology was assessed 
using standardized institutional grading. Due to the high OHSS risk, most autologous cycles underwent a "freezeall" followed by a subsequent frozen embryo transfer.

Patient's age, BMI, baseline AFC, total gonadotropin dose, serum $\mathrm{E}_{2}$ level, and number of follicles counted on trigger day were extracted from the electronic medical record. Laboratory parameters, embryo quality, and pregnancy outcomes were also collected.

\section{Outcomes}

The primary outcome was development of OHSS symptoms. We assessed the number of patients presenting with OHSSrelated symptoms with or without a formal OHSS diagnosis in the medical record. In patients formally diagnosed with OHSS, the syndrome was stratified by mild, moderate, or severe symptoms [9]. For patients without a formal OHSS diagnosis, their OHSS-related symptomatology was explicitly documented in the medical record by a medical provider. To decrease selection bias, the medical encounters reviewed were initiated by the patient specifically for assessment of OHSSrelated symptoms. The reported symptoms considered to be OHSS-related were moderate to severe abdominal bloating, persistent nausea or vomiting, and/or significant dyspnea. Factors considered potential confounders for development of OHSS were serum $E_{2}$ and the number of follicles counted on trigger day.

Secondary outcomes included oocyte recovery rate, oocyte maturity rate, total fertilization proportion, ICSI fertilization rate, ratio of good-quality embryos, and ongoing pregnancy rate. Oocyte recovery rate was defined as the number of oocytes retrieved divided by the number of follicles counted on trigger day measuring $>10 \mathrm{~mm}$ in size. A size cut-off of $10 \mathrm{~mm}$ in diameter was selected based on previous data demonstrating a low oocyte recovery rate from small follicles [48, 49]. Maturity rate was determined by the number of metaphase 2 oocytes (MII) divided by the number of oocytes retrieved and was only assessed in patients undergoing ICSI or elective oocyte cryopreservation. Total fertilization proportion was defined by the number of 2 pro-nuclei embryos (2PN) at fertilization check divided by the number of oocytes retrieved. ICSI fertilization rate was the number of $2 \mathrm{PN}$ divided by the number of MII. The ratio of good-quality embryos was calculated by the number of good-quality embryos divided by the number of 2PN. Goodquality cleavage stage embryos were defined by having a cell number of 7 to 10 and $<10 \%$ of the volume of the embryo was occupied by cell fragmentation based on a modified Veeck's grading system [50]. Based on the Gardner grading system, good-quality blastocysts were defined as having an expansion grade of 3 or higher, plus an inner cell mass and trophoectoderm grade of A or B [51]. Maternal age was regarded as a potential effect modifier on embryo quality. Ongoing pregnancy rate was defined by the number of live births or pregnancies beyond 20 weeks of gestational age at the time of analysis divided by the number of embryo transfer cycles. Factors considered potential effect modifiers on pregnancy outcomes were maternal age and the number of embryos transferred.

\section{Statistical analysis}

Baseline demographics, cycle characteristics, oocyte recovery, oocyte maturity, and fertilization rate were compared among all trigger groups using one-way analysis of variance. Logistic regression, controlling for serum $\mathrm{E}_{2}$ and number of follicles counted on trigger day, was used to define an association between a trigger group and development of OHSS. Embryo quality was compared among all triggers using the KruskalWallis test. A separate analysis was done comparing embryo quality, after adjusting for age, using a linear regression model. Pregnancy outcomes were compared, after adjusting for age and number of embryos transferred, using logistic regression. Pregnancy outcomes from donor oocyte cycles were adjusted only for the number of embryos transferred, while cumulative pregnancy rates per retrieval were adjusted for age only. Statistical significance was defined as a two-tailed $p$ value $<0.05$. All analyses were performed using $\mathrm{R}$ version 3.1.2 (R Foundation for Statistical Computing, Vienna, Austria). No missing data were encountered.

\section{Results}

Two hundred ninety-eight cycles met criteria to be included in this study. Of those cycles, 183 were autologous, 65 were donor, and 50 were elective oocyte cryopreservation cycles. Among the 298 IVF cycles, 39 received the novel trigger of $1500 \mathrm{IU}$ of hCG plus $450 \mathrm{IU}$ of FSH, 123 received $3300 \mathrm{IU}$ of hCG, 88 received GnRHa plus 1500 IU of hCG, and 48 received GnRHa only. One trigger failure occurred in the GnRHa plus 1500 IU of hCG group and three occurred in the GnRHa only group. Two of the failed triggers, both belonging to GnRHa only group, were re-triggered with hCG.

Baseline demographic and cycle characteristics are presented in Table 1. While there were no differences in BMI among all groups, statistically significant differences were found in age, baseline AFC, total gonadotropin dose, serum $E_{2}$, and number of follicles counted on trigger day. In a pairwise comparison, patients that received the low-dose hCG plus FSH trigger were significantly older than the GnRH agonist only and the GnRH agonist plus 1500 hCG groups. Patients that received the $3300 \mathrm{IU}$ hCG trigger had a significantly lower baseline AFC compared to patients in the GnRHa only and the GnRHa plus 1500 hCG groups. The average gonadotropin dose administered in the novel trigger group was significantly 
Table 1 Baseline demographics and cycle characteristics stratified by alternative trigger

\begin{tabular}{|c|c|c|c|c|c|}
\hline $\begin{array}{l}\text { Baseline demographic and } \\
\text { cycle characteristics }\end{array}$ & $\begin{array}{l}1500 \mathrm{IU} \text { hCG }+450 \mathrm{IU} \text { FSH } \\
(n=39)\end{array}$ & $\begin{array}{l}3300 \mathrm{IU} \text { hCG } \\
(n=123)\end{array}$ & $\begin{array}{l}\text { GnRHa }+1500 \mathrm{IU} \text { hCG } \\
(n=88)\end{array}$ & $\begin{array}{l}\text { GnRHa only } \\
(n=48)\end{array}$ & $p$ value \\
\hline Age (years) & $35.8^{\mathrm{a}}(6.0)$ & $34.4^{\mathrm{a}, \mathrm{b}}(5.5)$ & $32.9^{\mathrm{b}}(5.1)$ & $32.5^{\mathrm{b}}(6.4)$ & 0.01 \\
\hline $\operatorname{BMI}\left(\mathrm{kg} / \mathrm{m}^{2}\right)$ & $21.9(2.6)$ & $22.3(3.2)$ & $23.0(3.5)$ & $21.9(3.8)$ & 0.18 \\
\hline Baseline AFC $(n)$ & $24.9^{\mathrm{a}, \mathrm{b}}(12.7)$ & $20.6^{\mathrm{b}}(8.2)$ & $25.3^{\mathrm{a}}(10.4)$ & $29.8^{\mathrm{a}}(17.1)$ & $<0.001$ \\
\hline Total dose of gonadotropins (IU) & $2069.5^{\mathrm{b}}(669.6)$ & $1518.4^{\mathrm{a}}(750.5)$ & $1356.0^{\mathrm{a}}(546.7)$ & $1383.3^{\mathrm{a}}(631.5)$ & $<0.001$ \\
\hline $\begin{array}{l}\text { Serum estradiol on trigger day } \\
(\mathrm{pg} / \mathrm{ml})\end{array}$ & $6227.6^{\mathrm{a}, \mathrm{b}}(1023.9)$ & $5978.8^{\mathrm{b}}(956.0)$ & $6098.2^{\mathrm{a}, \mathrm{b}}(946.4)$ & $6536.8^{\mathrm{a}}(1648.7)$ & 0.03 \\
\hline $\begin{array}{l}\text { Total follicles counted on trigger } \\
\text { day }(n)\end{array}$ & $31.8^{\mathrm{a}, \mathrm{b}}(10.6)$ & $29.3^{\mathrm{a}}(8.5)$ & $34.3^{\mathrm{b}}(11.6)$ & $43.9^{\mathrm{c}}(15.2)$ & $<0.001$ \\
\hline
\end{tabular}

Values are expressed as mean (standard deviation). Failed triggers were excluded from the analysis

$I U$ international units, $h C G$ human chorionic gonadotropin, FSH follicle-stimulating hormone, GnRHa gonadotropin-releasing hormone agonist, $B M I$ body mass index, $A F C$ antral follicle count

${ }^{\mathrm{a}, \mathrm{b}, \mathrm{c}}$ Means sharing a superscript letter within a row denote no significant difference $(p>0.05)$

higher compared to all the other groups. Patients in the 3300 IU hCG trigger group had a significantly lower $E_{2}$ on trigger day when compared to the GnRHa only group. Last, the mean number of follicles counted on trigger day was significantly greater in the GnRHa only group compared to all groups, and the $3300 \mathrm{IU}$ hCG group had significantly fewer follicles than the GnRHa plus $1500 \mathrm{hCG}$ group.

In all, $70(22.9 \%)$ patients presented with OHSS-related symptoms, with or without a formal diagnosis. The most commonly reported symptoms were abdominal bloating and persistent nausea. Of the $38(12.7 \%)$ patients formally diagnosed with OHSS, 22 (7.4\%) had mild OHSS, 12 (4.0\%) had moderate OHSS, and 4 (1.3\%) were diagnosed with severe OHSS. The number of patients with OHSS-related symptoms or an OHSS diagnosis stratified by trigger strategy is presented in Table 2 . The moderate and severe symptoms experienced by the two patients in the GnRHa only group were provoked by administration of a second trigger using hCG after failing to respond to the initial GnRHa. The patient with moderate OHSS was re-triggered with $2000 \mathrm{IU}$ of hCG while the patient with severe OHSS received $3300 \mathrm{IU}$.

After controlling for serum $E_{2}$ and number of follicles counted on trigger day, receiving $3300 \mathrm{IU}$ of hCG rather than the novel trigger was associated with a 6.02 times increased odds of having any OHSS-related symptoms with or without a diagnosis [95\% confidence interval (CI) 1.9 to 27.2]. Similarly, compared to the novel trigger, receiving the GnRHa plus $1500 \mathrm{IU}$ of hCG trigger was associated with a 3.9 times increased odds of having OHSS-related symptoms (95\% CI 1.2 to 17.9). Focusing only on the development of mild, moderate, or severe OHSS, there was a trend toward statistical significance of an increased odds after receiving $3300 \mathrm{IU}$ hCG [odds ratio (OR) 4.2, 95\% CI 1.008 to 29.8] or GnRHa plus $1500 \mathrm{IU}$ of hCG trigger (OR 3.1, 95\% CI 0.72 to 21.6) compared to the novel trigger. In a subanalysis restricted to down-regulated cycles $(n=117)$, in which a risk-reduction alternative trigger was limited to an hCG-based trigger, there was a statistically significant increased odds of having OHSS-related symptoms in patients triggered with $3300 \mathrm{IU}$ hCG compared to the novel trigger (OR 10.3, 95\% CI 1.8 to 201.0). Only a trend toward statistical significance was observed when the outcome was defined as the development of mild, moderate, or severe OHSS (OR 4.4, 95\% CI 0.7 to 95.8).

Laboratory outcomes are presented in Table 3. Excluding cycles with a failed trigger, all cycles resulted in successful retrieval of oocytes. While there was a significant difference in oocyte recovery, there was no difference in maturation among all triggers. The novel trigger group had a significantly lower number of oocytes retrieved compared to the GnRHa only and the GnRHa plus $1500 \mathrm{IU}$ hCG trigger groups, but not when compared to those triggered with $3300 \mathrm{IU}$ of hCG. However, the number of follicles counted on trigger day usually correlates with the number of oocytes retrieved, but follicle number was significantly different among the trigger groups (Table 1). Therefore, oocyte recovery rate is a more equivalent parameter. In a pairwise comparison, the novel trigger group had a significantly lower oocyte recovery rate compared to the $3300 \mathrm{IU}$ hCG trigger group but not when compared to the other alternative triggers. Regarding fertilization outcomes, there were no differences among the triggers. A comparison of embryo quality is presented in Table 4 . A separate age-adjusted linear regression analysis also revealed no difference $(p<0.05)$ in embryo quality among all triggers (data not shown).

Due to the high OHSS risk in this population, only 45 patients received a fresh autologous embryo transfer, while most underwent embryo cryopreservation followed by a subsequent frozen embryo transfer. Among those 45 patients, 36 $(80 \%)$ were triggered with $3300 \mathrm{IU}$ of hCG. Within the 65 donor cycles, there were 59 fresh recipient embryo transfers. Blastocysts were transferred in $55.6 \%$ of autologous fresh cycles and in $79.7 \%$ of donor-recipient fresh transfers. There was a total of 284 subsequent autologous and donor- 
Table 2 Patients experiencing OHSS symptoms stratified by alternative trigger

\begin{tabular}{|c|c|c|c|c|c|c|c|c|}
\hline \multirow[t]{2}{*}{ OHSS outcomes } & \multicolumn{2}{|c|}{$\begin{array}{l}1500 \mathrm{IU} \text { hCG }+450 \mathrm{IU} \text { FSH } \\
(n=39)\end{array}$} & \multicolumn{2}{|c|}{$\begin{array}{l}3300 \mathrm{IU} \text { hCG } \\
(n=123)\end{array}$} & \multicolumn{2}{|c|}{$\begin{array}{l}\text { GnRHa }+1500 \mathrm{IU} \text { hCG } \\
(n=88)\end{array}$} & \multicolumn{2}{|c|}{$\begin{array}{l}\text { GnRHa only } \\
(n=48)\end{array}$} \\
\hline & $n$ & $\%$ & $n$ & $\%$ & $n$ & $\%$ & $n$ & $\%$ \\
\hline \multicolumn{9}{|l|}{ Patients with symptoms or a diagnosis of OHSS } \\
\hline OHSS-related symptoms without diagnosis ${ }^{\mathrm{a}}$ & 1 & 2.6 & 18 & 14.6 & 9 & 10.2 & 4 & 8.3 \\
\hline Mild OHSS & 1 & 2.6 & 8 & 6.5 & 9 & 10.2 & 4 & 8.3 \\
\hline Moderate OHSS & 0 & 0.0 & 7 & 5.7 & 4 & 4.5 & $1\left(0^{\mathrm{b}}\right)$ & 2.1 \\
\hline Severe OHSS & 1 & 2.6 & 1 & 0.8 & 1 & 1.1 & $1\left(0^{\mathrm{b}}\right)$ & 2.1 \\
\hline \multicolumn{9}{|l|}{ Summary totals } \\
\hline Total with mild, moderate, or severe OHSS & 2 & 5.1 & 16 & 13.0 & 14 & 15.9 & $6\left(4^{\mathrm{b}}\right)$ & $12.5\left(8.3^{\mathrm{b}}\right)$ \\
\hline Total with any OHSS-related symptoms & 3 & 7.7 & 34 & 27.6 & 23 & 26.1 & $10\left(8^{\mathrm{b}}\right)$ & $20.8\left(16.7^{\mathrm{b}}\right)$ \\
\hline
\end{tabular}

Values are expressed as number and percentage

OHSS ovarian hyperstimulation syndrome, $I U$ international units, $h C G$ human chorionic gonadotropin, $F S H$ follicle-stimulating hormone, GnRHa gonadotropin-releasing hormone agonist

${ }^{a}$ Denotes patients that reported OHSS-related symptoms but did not receive a formal diagnosis of OHSS after evaluation

${ }^{\mathrm{b}}$ Excludes patients that were re-triggered with hCG due to initial failed response to GnRHa-only trigger

recipient frozen embryo transfers (230 and 54 transfers, respectively), either transferring blastocyst or cleavage stage embryos ( 84.9 and $15.5 \%$, respectively). Among all frozen transfers, $30.3 \%$ of patients underwent pre-implantation genetic screening (PGS), warranting a frozen transfer regardless of OHSS risk.

Pregnancy outcomes are presented in Table 5. Within autologous cycles, analysis was limited to blastocyst frozen transfers without PGS, as this represented the largest subgroup. Initial outcome assessment included all transfers performed within this treatment cohort, followed by a separate analysis of the pregnancy outcomes of only the first embryo transfer to exclude the confounding effect of repeated patients. After adjusting for age and number of embryos transferred using logistic regression, there was no difference in ongoing pregnancy rates among all trigger groups. No difference in outcomes was also observed if only the first transfer performed was included in the analysis. Within donor cycles, pregnancy outcomes from fresh blastocyst transfers were analyzed, as this represented the largest cohort. Using logistic regression models to adjust for the number of embryos transferred, the ongoing pregnancy rate was not significantly different among the triggers. In addition, the cumulative ongoing pregnancy rate per retrieval for both autologous and donor cycles was not significantly different after adjusting for age.

\section{Discussion}

In this retrospective cohort study, a novel trigger using $1500 \mathrm{IU}$ of hCG plus $450 \mathrm{IU}$ of FSH, developed as a universal alternative for high-risk OHSS patients, demonstrated similar

Table 3 In vitro fertilization outcomes stratified by alternative trigger

\begin{tabular}{|c|c|c|c|c|c|}
\hline Laboratory outcomes & $\begin{array}{l}1500 \mathrm{IU} \text { hCG + } 450 \mathrm{IU} \text { FSH } \\
(n=39)\end{array}$ & $\begin{array}{l}3300 \mathrm{IU} \text { hCG } \\
(n=123)\end{array}$ & $\begin{array}{l}\text { GnRHa }+1500 \mathrm{IU} \text { hCG } \\
(n=88)\end{array}$ & $\begin{array}{l}\text { GnRHa only } \\
(n=48)\end{array}$ & $p$ value \\
\hline Mean oocytes retrieved & $24.6^{\mathrm{a}}(9.9)$ & $26.9^{\mathrm{a}}(9.0)$ & $30.9^{\mathrm{b}}(10.7)$ & $34.8^{\mathrm{b}}(11.8)$ & 0.001 \\
\hline Oocyte recovery rate & $0.95^{\mathrm{a}}(0.27)$ & $1.12^{\mathrm{b}}(0.25)$ & $1.07^{\mathrm{a}, \mathrm{b}}(0.22)$ & $1.09^{\mathrm{a}, \mathrm{b}}(0.22)$ & 0.01 \\
\hline Oocyte maturity rate, $\%$ & $77.1(16.9)$ & $77.9(12.1)$ & $79.3(14.7)$ & $82.3(12.0)$ & 0.31 \\
\hline ICSI fertilization rate, $\%$ & $80.8(15.8)$ & $81.2(16.6)$ & $81.5(22.5)$ & $84.7(7.3)$ & 0.81 \\
\hline Mean fertilization proportion, $\%$ & $63.8(16.7)$ & $62.2(16.7)$ & $65.2(19.2)$ & $66.2(15.5)$ & 0.56 \\
\hline
\end{tabular}

Values are expressed as a ratio (standard deviation) or percentage (standard deviation) where noted. Failed triggers were excluded from the analysis. Oocyte recovery rate was defined as the number of oocytes retrieved divided by the number of follicles counted on trigger day measuring $>10 \mathrm{~mm}$ in size $I U$ international units, $h C G$ human chorionic gonadotropin, FSH follicle-stimulating hormone, GnRHa gonadotropin-releasing hormone agonist, ICSI intracytoplasmic sperm injection

${ }^{\mathrm{a}, \mathrm{b}}$ Means sharing a superscript letter within a row denote no significant difference $(p>0.05)$ 
Table 4 Embryo quality stratified by trigger

\begin{tabular}{llllll}
\hline Good-quality embryo ratio & $\begin{array}{l}\text { 1500 IU hCG }+ \\
\text { 450 IU FSH }\end{array}$ & 3300 IU hCG & $\begin{array}{l}\text { GnRHa }+ \\
\text { 1500 IU hCG }\end{array}$ & GnRHa only & $p$ value \\
\hline Good-quality blastocyst ratio & $0.44(0.16)$ & $0.36(0.21)$ & $0.45(0.17)$ & $0.40(0.18)$ \\
Good-quality blastocyst and cleavage stage ratio & $0.45(0.16)$ & $0.38(0.22)$ & $0.44(0.17)$ & $0.40(0.17)$ & 0.07 \\
\hline
\end{tabular}

Values are expressed as a ratio of the number of good-quality embryos divided by the number of 2 pro-nuclei (standard deviation)

$I U$ international units, $h C G$ human chorionic gonadotropin, FSH follicle-stimulating hormone, GnRHa gonadotropin-releasing hormone agonist

IVF and pregnancy outcomes compared to conventionally used alternative triggers, and potentially decreased the risk of developing OHSS symptoms. These findings suggest that this novel trigger is superior to other alternative triggers containing hCG and provides a viable alternative to reduce the risk of OHSS in cases where a GnRHa trigger is not an option or has a high risk of failure.

Modification of the standard trigger medication used to induce final oocyte maturation is one major strategy employed to decrease the risk of OHSS. The use of a GnRHa trigger to induce an endogenous LH surge has been widely accepted to effectively mitigate the risk of OHSS by avoiding hCG, the main player in the pathogenesis of OHSS. Nonetheless, certain clinical scenarios precluding its use (i.e., down-regulated protocols and hypothalamic dysfunction) and the occasional insufficient pituitary response in normo-ovulatory patients limit the ability of the GnRHa trigger to completely eliminate the use of exogenous hCG [35]. In an effort to overcome this clinically relevant shortcoming, we strived to develop a comparable risk-reducing novel trigger that can be used in clinical situations where hCG cannot be avoided. To our knowledge, this is the first study to present the successful use of $1500 \mathrm{IU}$ of hCG plus 450 IU of FSH to induce oocyte maturation in patients undergoing IVF.

Human chorionic gonadotropin has a high degree of homology to LH, allowing it to function as a surrogate for the midcycle surge in assisted reproductive technologies. However, given the higher biopotency of hCG, the standard hCG trigger dose of 10,000 IU used in IVF leads to a significantly higher post-trigger LH activity compared to the natural LH surge [18]. Furthermore, its longer half-life and higher affinity for LH receptors additionally augments and prolongs its bioactivity $[16,18,19,52]$. Understanding the causal relationship between LH activity and OHSS, several studies in women undergoing IVF have attempted to find the lowest effective hCG dose that adequately promotes oocyte maturation. Interestingly, several mammalian studies investigating the varying LH threshold of different ovulatory events have found that lower LH activity is necessary for nuclear maturation compared to luteinization and follicular rupture [53-57]. For example, evidence in rats

Table 5 Pregnancy outcomes stratified by alternative trigger

\begin{tabular}{|c|c|c|c|c|}
\hline Pregnancy outcomes & $1500 \mathrm{IU}$ hCG + $450 \mathrm{IU}$ FSH & $3300 \mathrm{IU}$ hCG & GnRHa + 1500 IU hCG & GnRHa only \\
\hline \multicolumn{5}{|c|}{ Ongoing pregnancy rate for autologous FET blastocyst transfers with no PGS } \\
\hline Ongoing pregnancy rate $(\%)$ & $6 / 9(66.7)$ & $22 / 55(40.0)$ & $17 / 25(68.0)$ & $4 / 15(26.7)$ \\
\hline Adjusted odds ratio $^{\mathrm{a}}(95 \% \mathrm{CI})$ & Reference & $0.23(0.04,0.9)$ & $0.58(0.1,2.78)$ & $0.22(0.03,1.19)$ \\
\hline \multicolumn{5}{|c|}{ Ongoing pregnancy rate of first transfer for autologous FET blastocyst with no PGS } \\
\hline Ongoing pregnancy rate $(\%)$ & $4 / 5(80.0)$ & $12 / 25(48)$ & $11 / 15(73.3)$ & $1 / 5(20)$ \\
\hline Adjusted odds ratio $^{\mathrm{a}}(95 \% \mathrm{CI})$ & Reference & $0.17(0.007,1.55)$ & $0.38(0.01,4.32)$ & $0.06(0.001,1.18)$ \\
\hline \multicolumn{5}{|c|}{ Ongoing pregnancy rate for donor fresh blastocyst transfers } \\
\hline Ongoing pregnancy rate $(\%)$ & $3 / 5(60.0)$ & $8 / 12(66.7)$ & $12 / 17(70.6)$ & $5 / 11(45.5)$ \\
\hline Adjusted odds ratio $^{\mathrm{b}}(95 \% \mathrm{CI})$ & Reference & $2.22(0.21,22.10)$ & $2.32(0.22,22.69)$ & $0.55(0.05,4.73)$ \\
\hline \multicolumn{5}{|c|}{ Cumulative pregnancy rate per retrieval } \\
\hline Ongoing pregnancy rate $(\%)$ & $18 / 25(72.0)$ & $81 / 114(71.0)$ & $46 / 55(83.6)$ & $21 / 28(75.0)$ \\
\hline Adjusted odds ratio $^{c}(95 \% \mathrm{CI})$ & Reference & $0.94(0.33,2.46)$ & $1.53(0.46,4.91)$ & $0.80(0.22,2.90)$ \\
\hline
\end{tabular}

Values are expressed as number (\%)

$I U$ international units, $h C G$ human chorionic gonadotropin, FSH follicle-stimulating hormone, GnRHa gonadotropin-releasing hormone agonist, FET frozen embryo transfer, $P G S$ pre-implantation genetic screening, $C I$ confidence interval

${ }^{\text {a }}$ Logistic regression model adjusted for age and number of embryos transferred

${ }^{\mathrm{b}}$ Logistic regression model adjusted for number of embryos transferred only

${ }^{\mathrm{c}}$ Logistic regression model adjusted for age only 
reveals that only $5 \%$ of the mid-cycle surge is required for oocyte maturation compared to $85 \%$ that is required for ovulation [58]. These findings suggest that standard doses of hCG may be in excess for what is required to achieve oocyte maturation, the primary goal in IVF.

Among studies investigating the lowest effective dose of hCG in high-risk OHSS patients, triggering with $2500 \mathrm{IU}$ of hCG reported low to absent OHSS and successful retrieval of mature fertilizable oocytes resulting in viable pregnancies $[59,60]$. Compared to the standard hCG dose, one study did note a trend toward a lower oocyte recovery, maturity, and fertilization rate in the 2500 IU trigger group, but also a trend toward increased implantation and ongoing pregnancy rate [60]. A study reporting outcomes on 231 cycles triggered with $2000 \mathrm{IU}$ of hCG found that $11.7 \%$ had no oocytes retrieved [61]. Similarly, an older randomized study comparing $2000 \mathrm{IU}$ to the standard 5000 and 10,000 IU hCG dose in normal responders observed that a significantly higher number of patients receiving $2000 \mathrm{IU}$ had no oocytes recovered after laparoscopic retrieval $(22.7 \%$ vs. $4.5 \%$ and $1.9 \%$, respectively) [31]. The authors concluded that different follicles and/or patients may have a variable dose threshold to hCG as the number of oocytes retrieved and fertilization rates did not differ after a successful retrieval. In contrast, two studies also triggering with $2000 \mathrm{IU}$ did not report any failed retrievals $[62,63]$. A case report describing two patients who inadvertently injected $1000 \mathrm{IU}$ of hCG instead of the standard trigger dose found that although one patient had a failed retrieval, the other was successful and resulted in a viable pregnancy [64]. Although the lowest effective hCG trigger dose is yet to be determined, these findings overall demonstrate that much lower doses compared to the standard hCG dose can promote oocyte maturity, retrieval, fertilization, and pregnancy. Nevertheless, the occasional oocyte recovery failures reported in the studies triggering with 1000 and $2000 \mathrm{IU}$ of hCG led us to be apprehensive about developing a novel trigger using $1500 \mathrm{IU}$ of hCG alone. This concern led us to examine ways to potentiate the hCG effect without having to increase the dose.

During the natural cycle, a concomitant LH and FSH surge occurs to induce ovulation [39]. A specific role for the FSH surge is not well understood; nonetheless, FSH has been shown to induce LH receptors on luteinizing granulosa cells [40], promote resumption of oocyte meiosis [41, 65, 66], and stimulate plasminogen activator activity for follicular rupture [67]. Furthermore, a bolus of FSH has been shown to independently induce ovulation in rodents and macaques [42-45]. Similar findings were also reported in humans after a patient undergoing IVF inadvertently self-administered a bolus of FSH instead of hCG [68]. Its biological importance can be further postulated after a randomized study found significantly higher oocyte recovery and fertilization with the addition of a 450 IU FSH bolus to the standard hCG trigger dose [46].
Mounting evidence for the potential ovulatory role of the FSH surge suggests that the addition of an FSH bolus to a very low dose of hCG may potentiate the $\mathrm{LH}$ effects required to induce ovulatory events. By combining the existing data, we designed a novel trigger of $1500 \mathrm{IU}$ of hCG with the addition of $450 \mathrm{IU}$ of FSH to theoretically potentiate the hCG effect and overcome the risk of failed final oocyte maturation while decreasing the OHSS risk.

In contrast to previous studies reporting a failure to retrieve any oocytes in a subset of patients receiving only 1000 to $2000 \mathrm{IU}$ of hCG [31, 61, 64], all patients receiving the novel trigger in our current study underwent successful oocyte retrieval. Notably, the mean post-trigger hCG serum level in patients receiving the novel trigger was $40.5 \mathrm{IU} / 1$ and ranged from 18.9 to $64.03 \mathrm{IU} / 1$. Serum laboratories were drawn on average $12 \mathrm{~h}$ post-trigger. Except for a lower oocyte recovery rate compared to the $3300 \mathrm{IU}$ hCG trigger, the novel trigger did not significantly differ in any other IVF outcomes compared to the other alternative triggers. As previously hypothesized [31], the lower oocyte recovery rate observed may be reflective of a size-dependent follicular response to a decreased LH activity necessary to induce oocyte-cumulus complex detachment from the follicular wall facilitating aspiration. Since the size of follicles resulting in recovered oocytes was not recorded, it is not possible to make any definitive conclusions about the ability to successfully aspirate an oocyte based on the follicular size. The total and ICSI fertilization rate of the novel trigger was the same compared to all other trigger groups, demonstrating that such a low dose of hCG potentiated by FSH allows adequate cytoplasmic maturation for normal fertilization to occur. Overall, use of this novel trigger results in similar laboratory outcomes compared to conventionally utilized alternative triggers used in high-risk OHSS patients.

Due to the high risk of OHSS, most patients did not receive an autologous fresh transfer and underwent a "freeze-all" for their safety. However, there were a total of four autologous fresh embryo transfers in the novel trigger group resulting in two live births and no development of OHSS. The luteal support used for all four fresh embryo transfers was intramuscular progesterone in oil and oral micronized estradiol. Moreover, the live births arising from frozen embryos further demonstrate that the novel trigger has the ability to induce appropriate oocyte competence to promote normal embryo development resulting in a live birth. An earlier study noting a trend toward increased ongoing pregnancy rate in patients triggered with $2500 \mathrm{IU}$ of hCG compared to 5000 and 10,000 IU hypothesized a potential beneficial effect of lowering the hCG dose and simulating a more physiologic natural surge [60]. In parallel, although not significant, the pregnancy outcomes in the autologous frozen transfer cycles were higher in the novel trigger group compared to the $3300 \mathrm{IU}$ hCG trigger and the GnRHa only trigger groups (66.7\% vs. $40.0 \%$ and $26.7 \%$, respectively). 
With the advent of the GnRHa trigger to induce an endogenous LH surge, clinicians can avoid the use of any hCG [28, 69, 70]. While the widespread use of a GnRHa trigger has largely eliminated the development of OHSS in many IVF centers [34, $71,72]$, similar to other reports [73-75], four patients in our highrisk cohort were diagnosed with OHSS after triggering with GnRHa. One major downside of the GnRHa trigger is its inability to induce an endogenous LH surge in down-regulated stimulation cycles or in patients with hypothalamic dysfunction. In contrast, $1500 \mathrm{IU}$ of hCG plus FSH trigger can be utilized to induce oocyte maturation across all stimulations. Furthermore, the occasional failure of the GnRHa to elicit an endogenous $\mathrm{LH}$ surge in normo-ovulatory patients is of particular concern due to the high risk of developing severe OHSS if a subsequent hCG trigger is administered [76]. There were a total of four patients in our study that failed to respond to the GnRHa trigger, despite reporting a history of regular menstrual cycles. Unsurprisingly, the two patients that were re-triggered with hCG (2000 to $3300 \mathrm{IU})$ subsequently developed moderate to severe OHSS. The limited ability to conclusively identify all the patients with inadequate pituitary LH stores [35, 37, 38, 77] has consequently prompted the practice of adding $1500 \mathrm{IU}$ hCG co-trigger to the GnRHa trigger to avoid trigger failure [78, 79]. However, the addition of an hCG co-trigger is not without risk of OHSS [80].

Although not statistically significant, here we demonstrated that a higher percentage of patients using an hCG co-trigger developed OHSS compared to the novel trigger (15.9\% vs. $5.1 \%$ ) despite having similar serum estradiol and follicle number on trigger day-markers often used to assess pre-trigger OHSS risk. Even though the administered hCG dose is the same in both triggers, the increased OHSS symptoms may be due to a higher cumulative LH activity induced by the GnRHa plus the hCG co-trigger. In parallel, the odds ratio of developing OHSS-related symptoms among those receiving $3300 \mathrm{IU}$ of hCG was significantly higher when compared to receiving the novel trigger despite having a lower $\mathrm{E}_{2}$ and follicle number on trigger day. These findings are compatible with previous studies noting that $3300 \mathrm{IU}$ of hCG does not decrease the risk of OHSS compared to standard hCG dosing [81]. Our study demonstrates that the novel trigger can potentially be used to circumvent the development of OHSS when the use of the GnRHa trigger is not an option.

This study has important limitations. The average BMI in all trigger groups was within normal limits, ranging from 21.9 to 23.0, and did not differ between groups. However, since BMI can potentially affect the pharmacokinetics of medications, we cannot assess if the low-dose hCG plus FSH would be sufficient to induce adequate oocyte maturation in patients with an elevated BMI, as the highest BMI in patients who received the novel trigger was 27.4. Selection bias could exist between the trigger groups as serum $\mathrm{E}_{2}$ levels and follicles counted, markers of pre-trigger OHSS risk, may heavily impact clinical management. For example, patients triggered with 3300 IU had a significantly lower baseline AFC, lower serum estradiol, and less number of follicles on the day of trigger compared to patients receiving the GnRHa-based trigger. The non-random trigger selection in our study may lead to significant differences in variables that may influence the outcome. Furthermore, the heterogeneity of the protocols and treatments included is another weakness of the study. Unfortunately, the ability to carry out a large prospective randomized clinical trial to assess the best trigger alternative in patients at highest risk for severe OHSS would be difficult given the overall low prevalence of severe symptoms [10]. Also, while we postulate that 450 IU of FSH helped to potentiate oocyte maturity in the $1500 \mathrm{IU}$ hCG group, we did not compare this group to $1500 \mathrm{IU}$ of hCG alone, so the precise role of FSH remains to be elucidated in future research.

Another limitation is the possibility of under-reporting the incidence of mild and moderate OHSS in this study cohort, as the diagnosis of OHSS was determined after the patient initiated the medical encounter. However, there are two major ways the impact of this limitation is reduced. First, all patients undergoing ovarian stimulation are educated about the signs and symptoms of OHSS during the required IVF orientation and consent signing consult. Patients who are considered to be very high risk for OHSS pre-trigger, such as patients included in this study, are further warned about the high likelihood of developing OHSS and instructed to closely monitor signs and symptoms. Second, all patients undergoing an oocyte retrieval receive a telephone call 1 to 3 days post-procedure by one of our nurses to report on the IVF laboratory outcome of their cycle and to follow up on the patient's clinical status. During this phone call, the patient can report symptoms suspicious of a complication that will initiate a medical encounter with a physician or nurse practitioner. A future prospective study can avoid under-reporting of OHSS incidence by requiring that all patients have a post-retrieval medical evaluation.

\section{Conclusion}

Our results suggest that a novel trigger using $1500 \mathrm{IU}$ of hCG plus $450 \mathrm{IU}$ of $\mathrm{FSH}$, developed as an alternative strategy to mitigate OHSS, is capable of reactivating oocyte meiosis and promoting cytoplasmic maturation changes leading to mature and fertilizable oocytes capable of normal embryonic development resulting in a live birth. Most importantly, this novel trigger may provide a superior alternative in down-regulated cycles and in patients with hypothalamic dysfunction where alternative trigger strategies to circumvent OHSS are limited to hCG.

\section{Compliance with ethical standards}

Conflicts of interest The authors declare that they have no conflict of interest. 


\section{References}

1. Navot D, Relou A, Birkenfeld A, Rabinowitz R, Brzezinski A, Margalioth E. Risk factors and prognostic variables in the ovarian hyperstimulation syndrome. Am J Obstet Gynecol. 1988;159(1): 210-5.

2. Delvigne A, Demoulin A, Smitz J, Donnez J, Koninckx P, Dhont $\mathrm{M}$, et al. The ovarian hyperstimulation syndrome in in-vitro fertilization: a Belgian multicentric study. I. Clinical and biological features. Hum Reprod. 1993;8(9):1353-60.

3. Enskog A, Henriksson M, Unander M, Nilsson L, Brännström M. Prospective study of the clinical and laboratory parameters of patients in whom ovarian hyperstimulation syndrome developed during controlled ovarian hyperstimulation for in vitro fertilization. Fertil Steril. 1999;71(5):808-14.

4. Schenker JG, Polishuk WZ. Ovarian hyperstimulation syndrome. Obstet Gynecol. 1975;46(1):23-8.

5. Goldsman MP, Pedram A, Dominguez CE, Ciuffardi I, Levin E, Asch RH. Increased capillary permeability induced by human follicular fluid: a hypothesis for an ovarian origin of the hyperstimulation syndrome. Fertil Steril. 1995;63(2):268-72.

6. Mor YS, Schenker JG. Ovarian hyperstimulation syndrome and thrombotic events. Am J Reprod Immunol. 2014;72(6):541-8.

7. Balasch J, Carmona F, Llach J, Arroyo V, Jové I, Vanrell JA. Acute prerenal failure and liver dysfunction in a patient with severe ovarian hyperstimulation syndrome. Hum Reprod. 1990;5(3):348-51.

8. Abramov Y, Elchalal U, Schenker JG. Pulmonary manifestations of severe ovarian hyperstimulation syndrome: a multicenter study. Fertil Steril. 1999;71(4):645-51.

9. Golan A, Ron-el R, Herman A, Soffer Y, Weinraub Z, Caspi E. Ovarian hyperstimulation syndrome: an update review. Obstet Gynecol Surv. 1989;44(6):430-40.

10. Delvinge A, Rozenberg S. Epidemiology and prevention of ovarian hyperstimulation syndrome (OHSS): a review. Hum Reprod Update. 2002;8(6):559-77.

11. McClure N, Healy DL, Rogers PAW, Sullivan J, Robertson DM, Haning RV, et al. Vascular endothelial growth factor as capillary permeability agent in ovarian hyperstimulation syndrome. Lancet. 1994;344(8917):235-6.

12. Levin ER, Rosen GF, Cassidenti DL, Yee B, Meldrum D, Wisot A, et al. Role of vascular endothelial cell growth factor in ovarian hyperstimulation syndrome. J Clin Invest. 1998;102(11):1978-85.

13. Bergh PA, Navot D. Ovarian hyperstimulation syndrome: a review of pathophysiology. J Assist Reprod Genet. 1992;9(5):429-38.

14. Elchalal U, Schenker JG. The pathophysiology of ovarian hyperstimulation syndrome — views and ideas. Hum Reprod. 1997;12(6): 1129-37.

15. Wallach E, Schenker JG, Weinstein D. Ovarian hyperstimulation syndrome: a current survey. Fertil Steril. 1978;30(3):255-68.

16. Yen SS, Llerena O, Little B, Pearson OH. Disappearance rates of endogenous luteinizing hormone and chorionic gonadotropin in man. J Clin Endocrinol Metab. 1968;28(12):1763-7.

17. Schlach DS, Parlow AF, Boon RC, Reichlin S. Measurement of luteinizing hormone in plasma by radioimmunoassay. J Clin Invest. 1968;47(3):665-78.

18. Rizkallah T, Gurpide E, Vande Wiele RL. Metabolism of HCG in man. J Clin Endocrinol Metab. 1969;29(1):92-100.

19. Rao CV. Differential properties of human chorionic gonadotrophin and human luteinizing hormone binding to plasma membranes of bovine corpora lutea. Acta Endocrinol. 1979;90(4):696-710.

20. Kashyap S, Parker K, Cedars MI, Rosenwaks Z. Ovarian hyperstimulation syndrome prevention strategies: reducing the human chorionic gonadotropin trigger dose. Semin Reprod Med. 2010;28(6):475-85.
21. Neulen J, Yan Z, Raczek S, Weindel K, Keck C, Weich HA, et al. Human chorionic gonadotropin-dependent expression of vascular endothelial growth factor/vascular permeability factor in human granulosa cells: importance in ovarian hyperstimulation syndrome. J Clin Endocrinol Metab. 1995;80(6):1967-71.

22. Wang T-H, Horng S-G, Chang C-L, Wu H-M, Tsai Y-J, Wang H-S, et al. Human chorionic gonadotropin-induced ovarian hyperstimulation syndrome is associated with up-regulation of vascular endothelial growth factor. J Clin Endocrinol Metab. 2002;87(7):3300-8.

23. Schenker JG. Prevention and treatment of ovarian hyperstimulation. Hum Reprod. 1993;8(5):653-9.

24. Grochowski D, Wolczynski S, Kuczynski W, Domitrz J, Szamatowicz J, Szamatowicz M. Correctly timed coasting reduces the risk of ovarian hyperstimulation syndrome and gives good cycle outcome in an in vitro fertilization program. Gynecol Endocrinol. 2001;15(3):234-8.

25. D'Angelo A, Amso N. Embryo freezing for preventing ovarian hyperstimulation syndrome. Cochrane Database Syst Rev. 2007;3: CD002806.

26. Leitao VMS, Moroni RM, Seko LMD, Nastri CO, Martins WP Cabergoline for the prevention of ovarian hyperstimulation syndrome: systematic review and meta-analysis of randomized controlled trials. Fertil Steril. 2013;101(3):664-675.e7.

27. Youssef MA, Al-Inany HG, Evers JL, Aboulghar M. Intra-venous fluids for the prevention of severe ovarian hyperstimulation syndrome. Cochrane Database Syst Rev. 2011;2:CD001302.

28. Itskovitz J, Boldes R, Levron J, Erlik Y, Kahana L, Brandes JM. Induction of preovulatory luteinizing hormone surge and prevention of ovarian hyperstimulation syndrome by gonadotropinreleasing hormone agonist. Fertil Steril. 1991;56(2):213-20.

29. Youssef MAFM, Van der Veen F, Al-Inany HG, Mochtar MH, Griesinger G, Nagi Mohesen M, et al. Gonadotropin-releasing hormone agonist versus HCG for oocyte triggering in antagonistassisted reproductive technology. Cochrane Database Syst Rev. 2014;10:CD008046.

30. Abbara A, Jayasena CN, Christopoulos G, Narayanaswamy S, IzziEngbeaya C, Nijher GMK, et al. Efficacy of kisspeptin-54 to trigger oocyte maturation in women at high risk of ovarian hyperstimulation syndrome (OHSS) during in vitro fertilization (IVF) therapy. J Clin Endocrinol Metab. 2015;100(9):3322-31.

31. Abdalla HI, Ah-Moye M, Brinsden P, Howe DL, Okonofua F, Craft I. The effect of the dose of human chorionic gonadotropin and the type of gonadotropin stimulation on oocyte recovery rates in an in vitro fertilization program. Fertil Steril. 1987;48(6):958-63.

32. Wikland M, Borg J, Forsberg AS, Jakobsson AH, Svalander P, Waldenström U. Human chorionic gonadotrophin selfadministered by the subcutaneous route to induce oocyte maturation in an in-vitro fertilization and embryo transfer programme. Hum Reprod. 1995;10(7):1667-70.

33. Gonen Y, Balakier H, Powell W, Casper RF. Use of gonadotropinreleasing hormone agonist to trigger follicular maturation for in vitro fertilization. J Clin Endocrinol Metab. 1990;71(4):918-22.

34. Engmann L, DiLuigi A, Schmidt D, Nulsen J, Maier D, Benadiva C. The use of gonadotropin-releasing hormone $(\mathrm{GnRH})$ agonist to induce oocyte maturation after cotreatment with GnRH antagonist in high-risk patients undergoing in vitro fertilization prevents the risk of ovarian hyperstimulation syndrome: a prospective randomized controlled study. Fertil Steril. 2008;89(1):84-91.

35. Chang FE, Beall SA, Cox JM, Richter KS, DeCherney AH, Levy MJ. Assessing the adequacy of gonadotropin-releasing hormone agonist leuprolide to trigger oocyte maturation and management of inadequate response. Fertil Steril. 2016;106(5):1093-1100.e3.

36. Honnma H, Hashiba Y, Asada Y, Endo T. Failure of triggering oocyte maturation with a GnRH agonist in polycystic ovary syndrome: two case reports. Eur J Obstet Gynecol Reprod Biol. 2011;157(2):239-40. 
37. Kummer NE, Feinn RS, Griffin DW, Nulsen JC, Benadiva CA, Engmann LL. Predicting successful induction of oocyte maturation after gonadotropin-releasing hormone agonist (GnRHa) trigger. Hum Reprod. 2013;28(1):152-9.

38. Meyer L, Murphy LA, Gumer A, Reichman DE, Rosenwaks Z, Cholst IN. Risk factors for a suboptimal response to gonadotropin-releasing hormone agonist trigger during in vitro fertilization cycles. Fertil Steril. 2015;104(3):637-42.

39. Hoff JD, Quigley ME, Yen SSC. Hormonal dynamics at midcycle: a reevaluation. J Clin Endocrinol Metab. 1983;57(4):792-6.

40. Tapanainen JS, Lapolt PS, Perlas E, Hsueh AJ. Induction of ovarian follicle luteinization by recombinant follicle-stimulating hormone. Endocrinology. 1993;133(6):2875-80.

41. Zelinski-Wooten MB, Hutchison JS, Hess DL, Wolf DP, Stouffer RL. Follicle stimulating hormone alone supports follicle growth and oocyte development in gonadotrophin-releasing hormone antagonist-treated monkeys. Hum Reprod. 1995;10(7):1658-66.

42. Galway AB, Lapolt PS, Tsafriri A, Dargan CM, Boime I, Hsueh AJW. Recombinant follicle-stimulating hormone induces ovulation and tissue plasminogen activator expression in hypophysectomized rats. Endocrinology. 1990;127(6):3023-8.

43. Zelinski-Wooten MB, Hutchison JS, Hess DL, WoIf DP, Stouffer RL. A bolus of recombinant human follicle stimulating hormone at midcycle induces periovulatory events following multiple follicular development in macaques. Hum Reprod. 1998;13(3):554-60.

44. Rice VC, Zusmanis K, Malter H, Mitchell-Leef D. Pure FSH alone induces ovulation and subsequent pregnancy in the mouse resulting in fetal development. Life Sci. 1993;53(1):31-9.

45. Wang XN, Greenwald GS. Human chorionic gonadotropin or human recombinant follicle-stimulating hormone (FSH)-induced ovulation and subsequent fertilization and early embryo development in hypophysectomized FSH-primed mice. Endocrinology. 1993;132(5):2009-16.

46. Lamb JD, Shen S, McCulloch C, Jalalian L, Cedars MI, Rosen MP. Follicle-stimulating hormone administered at the time of human chorionic gonadotropin trigger improves oocyte developmental competence in in vitro fertilization cycles: a randomized, doubleblind, placebo-controlled trial. Fertil Steril. 2011;95(5):1655-60.

47. Papanikolaou EG, Pozzobon C, Kolibianakis EM, Camus M, Tournaye H, Fatemi HM, et al. Incidence and prediction of ovarian hyperstimulation syndrome in women undergoing gonadotropinreleasing hormone antagonist in vitro fertilization cycles. Fertil Steril. 2006;85(1):112-20.

48. Rosen MP, Zamah AM, Shen S, Dobson AT, McCulloch CE, Rinaudo PF, et al. The effect of follicular fluid hormones on oocyte recovery after ovarian stimulation: FSH level predicts oocyte recovery. Reprod Biol Endocrinol. 2009;7:35.

49. Scott RT, Hofmann GE, Muasher SJ, Acosta AA, Kreiner DK, Rosenwaks Z. Correlation of follicular diameter with oocyte recovery and maturity at the time of transvaginal follicular aspiration. $\mathrm{J}$ In Vitro Fert Embryo Transf. 1989;6(2):73-5.

50. Veeck LL. The morphological assessment of human oocytes and early conception. In: Keel BA, Webste BW, editors. Handbook of the laboratory diagnosis and treatment of infertility. Boca Raton: CRC Press; 1990. p. 353-69.

51. Gardner DK, Schoolcraft W. In vitro culture of human blastocysts. In: Toward reproductive certainty: fertility and genetics beyond 1999: the plenary proceedings of the 11th World Congress on In Vitro Fertilization and Human Reproductive Genetics. Pearl River, NY:Parthenon; 1999. p. 378-88.

52. Damewood MD, Shen W, Zacur HA, Schlaff WD, Rock JA, Wallach EE. Disappearance of exogenously administered human chorionic gonadotropin. Fertil Steril. 1989;52(3):398-400.

53. Bomsel-Helmreich O, Vu N, Huyen L, Durand-Gasselin I. Effects of varying doses of HCG on the evolution of preovulatory rabbit follicles and oocytes. Hum Reprod. 1989;4(6):636-42.
54. Zelinski-Wooten MB, Lanzendorf SE, Wolf DP, Chandrasekher YA, Stouffer RL. Titrating luteinizing hormone surge requirements for ovulatory changes in primate follicles. I. Oocyte maturation and corpus luteum function. J Clin Endocrinol Metab. 1991;73(3):57783.

55. Zelinski-Wooten MB, Hutchison JS, Chandrasekher YA, Wolf DP, Stouffer RL. Administration of human luteinizing hormone (hLH) to macaques after follicular development: further titration of LH surge requirements for ovulatory changes in primate follicles. $\mathrm{J}$ Clin Endocrinol Metab. 1992;75(2):502-7.

56. Chandrasekher YA, Hutchison JS, Zelinski-Wooten MB, Hess DL, Wolf DP, Stouffer RL. Initiation of periovulatory events in primate follicles using recombinant and native human luteinizing hormone to mimic the midcycle gonadotropin surge. J Clin Endocrinol Metab. 1994;79(1):298-306.

57. Zelinski-Wooten MB, Hutchison JS, Trinchard-Lugan I, Hess DL, Wolf DP, Stouffer RL. Initiation of periovulatory events in gonadotrophin-stimulated macaques with varying doses of recombinant human chorionic gonadotrophin. Hum Reprod. 1997;12(9): 1877-85.

58. Peluso JJ. Role of the amplitude of the gonadotropin surge in the rat. Fertil Steril. 1990;53(1):150-4.

59. Nargund G, Hutchison L, Scaramuzzi R, Campbell S. Low-dose HCG is useful in preventing OHSS in high-risk women without adversely affecting the outcome of IVF cycles. Reprod BioMed Online. 2007;14(6):682-5.

60. Kolibianakis EM, Papanikolaou EG, Tournaye H, Camus M, Van Steirteghem AC, Devroey P. Triggering final oocyte maturation using different doses of human chorionic gonadotropin: a randomized pilot study in patients with polycystic ovary syndrome treated with gonadotropin-releasing hormone antagonists and recombinant follicle-stimulating horm. Fertil Steril. 2007;88(5):1382-8.

61. Smith B, Porter R, Ahuja K, Craft I. Ultrasonic assessment of endometrial changes in stimulated cycles in an in vitro fertilization and embryo transfer program. J In Vitro Fert Embryo Transf. 1984;1(4):233-8.

62. Ahuja KK, Smith W, Tucker M, Craft I. Successful pregnancies from the transfer of pronucleate embryos in an outpatient in vitro fertilization program. Fertil Steril. 1985;44(2):181-4.

63. Chen X, Chen SL, He YX, Ye DS. Minimum dose of hCG to trigger final oocyte maturation and prevent OHSS in a long GnRHa protocol. J Huazhong Univ Sci Technol Med Sci. 2013;33(1):133-6.

64. Ișik AZ, Vicdan K. Borderline form of empty follicle syndrome: is it really an entity? Eur J Obstet Gynecol Reprod Biol. 2000;88(2): 213-5.

65. Andersen CY, Leonardsen L, Ulloa-Aguirre A, Barrios-De-Tomasi J, Moore L, Byskov AG. FSH-induced resumption of meiosis in mouse oocytes: effect of different isoforms. Mol Hum Reprod. 1999;5(8):726-31.

66. Yding AC. Effect of FSH and its different isoforms on maturation of oocytes from pre-ovulatory follicles. Reprod BioMed Online. 2002;5(3):232-9.

67. Strickland S, Beers WH. Studies on the role of plasminogen activator in ovulation. In vitro response of granulosa cells to gonadotropins, cyclic nucleotides, and prostaglandins. J Biol Chem. 1976;251(18):5694-702.

68. Bianchi V, Dal Prato L, Maccolini A, Mazzone S, Borini A. Inadvertent recombinant human follicle stimulating hormone bolus instead of human chorionic gonadotrophin leads to the retrieval of competent oocytes in IVF program. Fertil Steril. 2009;92(5):1747.

69. Humaidan P, Kol S, Papanikolaou EG. GnRH agonist for triggering of final oocyte maturation: time for a change of practice? Hum Reprod Update. 2011;17(4):510-24.

70. Griesinger G, Diedrich K, Devroey P, Kolibianakis EM. GnRH agonist for triggering final oocyte maturation in the GnRH 
antagonist ovarian hyperstimulation protocol: a systematic review and meta-analysis. Hum Reprod Update. 2006;12(2):159-68.

71. Bodri D, Guillén JJ, Trullenque M, Schwenn K, Esteve C, Coll O. Early ovarian hyperstimulation syndrome is completely prevented by gonadotropin releasing hormone agonist triggering in high-risk oocyte donor cycles: a prospective, luteal-phase follow-up study. Fertil Steril. 2010;93(7):2418-20.

72. Devroey P, Polyzos NP, Blockeel C. An OHSS-free clinic by segmentation of IVF treatment. Hum Reprod. 2011;26(10):2593-7.

73. Kol S, Lewit N, Itskovitz-Eldor J. Ovarian hyperstimulation: effects of GnRH analogues. Ovarian hyperstimulation syndrome after using gonadotrophin-releasing hormone analogue as a trigger of ovulation: causes and implications. Hum Reprod. 1996;11(6): $1143-4$.

74. Gurbuz AS, Gode F, Ozcimen N, Isik AZ. Gonadotrophin-releasing hormone agonist trigger and freeze-all strategy does not prevent severe ovarian hyperstimulation syndrome: a report of three cases. Reprod BioMed Online. 2014;29(5):541-4.

75. Fatemi HM, Popovic-Todorovic B, Humaidan P, Kol S, Banker M, Devroey $\mathrm{P}$, et al. Severe ovarian hyperstimulation syndrome after gonadotropin-releasing hormone $(\mathrm{GnRH})$ agonist trigger and "freeze-all" approach in GnRH antagonist protocol. Fertil Steril. 2014;101(4):1008-11.

76. Imoedemhe DA, Sigue AB, Pacpaco EL, Olazo AB. Stimulation of endogenous surge of luteinizing hormone with gonadotropin- releasing hormone analog after ovarian stimulation for in vitro fertilization. Fertil Steril. 1991;55(2):328-32.

77. Shapiro BS, Daneshmand ST, Restrepo H, Garner FC, Aguirre M, Hudson C. Efficacy of induced luteinizing hormone surge after "trigger" with gonadotropin-releasing hormone agonist. Fertil Steril. 2011;95(2):826-8.

78. Shapiro BS, Daneshmand ST, Garner FC, Aguirre M, Thomas S. Gonadotropin-releasing hormone agonist combined with a reduced dose of human chorionic gonadotropin for final oocyte maturation in fresh autologous cycles of in vitro fertilization. Fertil Steril. 2008;90(1):231-3.

79. Shapiro BS, Daneshmand ST, Garner FC, Aguirre M, Hudson C. Comparison of "triggers" using leuprolide acetate alone or in combination with low-dose human chorionic gonadotropin. Fertil Steril. 2011;95(8):2715-7.

80. O’Neill KE, Senapati S, Maina I, Gracia C, Dokras A. GnRH agonist with low-dose hCG (dual trigger) is associated with higher risk of severe ovarian hyperstimulation syndrome compared to $\mathrm{GnRH}$ agonist alone. J Assist Reprod Genet. 2016;33(9):1175-84.

81. Schmidt DW, Maier DB, Nulsen JC, Benadiva CA. Reducing the dose of human chorionic gonadotropin in high responders does not affect the outcomes of in vitro fertilization. Fertil Steril. 2004;82(4): $841-6$. 